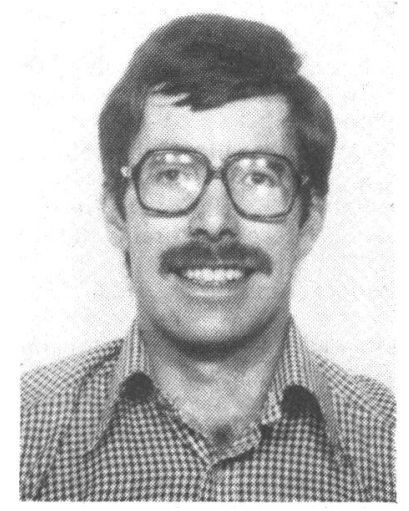

\title{
PREDICTING RUNNING SPEED FROM A SIMPLE QUESTIONNAIRE
}

\author{
M. J. CAMPBELL, PhD \\ Community Medicine and Medical Statistics, University of Southampton, South Block, \\ Southampton General Hospital, Southampton SO9 4XY
}

M. J. Campbell

\section{ABSTRACT}

Of 221 competitors in a University half marathon in 1983, 98 replied to a questionnaire before the race which asked for details of training, age, height, weight and resting pulse rate. Finishing times of all competitors were recorded. In a multiple regression analysis significant predictors of running speed were: amount of training, expressed as distance run per week and number of weeks training for the event, the Body Mass Index (weight/height ${ }^{2}$ ) and resting pulse rate. We conclude that for assessing running speed amongst competitors with similar amounts of training, the Body Mass Index and the resting pulse rate are useful substitutes for more elaborate and expensive measures.

Key words: Distance running, Resting pulse rate, Body Mass Index.

\section{INTRODUCTION}

A number of studies (Thomas et al, 1983; Tanaka and Matsuura, 1982; Costill et al, 1976; Hartung, 1982) have shown how a combination of anthropometric and physiological attributes can predict performance in distance running. However, these studies have been on trained athletes, and the measurement of the attributes often require both skilled operators and expensive equipment. A retrospective study by Khosla and Campbell (1982) of a selected sample of runners in a "fun-run" marathon reported that resting pulse rate, measured some time after the race, was negatively correlated with running speed during the race. Unfortunately these results cannot be used to derive a true correlation between running speed and resting pulse rate because the runners were selected to include some of the fastest and some of the slowest runners, and it is well known that selection in this manner will bias the correlation coefficient (Armitage, 1971, p. 159).

Anthropometric variables have been shown to be as good as physiological variables such as maximum oxygen uptake $\left(\mathrm{VO}_{2} \max \right)$ at predicting distance running performance, although for shorter distances physiological variables are more important (Tanaka and Matsuura, 1982). Important anthropometric variables such as height and weight can be reliably self-reported (Stewart, 1982) and thus could be incorporated into a simple questionnaire to predict distance running performance.

The aims of the present study were (1) to test the validity of a self-measured pulse rate (2) to investigate in more detail the relationship between resting pulse rate and running speed and $(3)$ to examine whether a simple questionnaire, using selfreported attributes could accurately predict performance in a half-marathon race of runners with a wide variety of fitness.

\section{METHODS}

The University of Southampton Physical Education Department organise an annual half marathon race of $21.1 \mathrm{~km}(13.1$ miles). Immediately before the race in March 1983 a question. naire was circulated to about $\mathbf{3 0 0 0}$ intending competitors. It asked questions regarding sex, smoking habits, age, height, weight, number of miles per week and number of weeks the competitor had been training for the event. For competitors who are training throughout the year, a nominal value of " 52 " was recorded. In addition the competitor was asked to record his or her resting pulse rate. The recommended procedure was to take this over a complete minute after the evening meal, to remain seated for a further five minutes and then take the pulse rate again. After the race the finishing times of all eventual 221 competitors who completed the course were obtained.

To investigate which variables best characterise obesity, from weight $(\mathrm{Wt})(\mathrm{kg})$ and height $(\mathrm{Ht})(\mathrm{m})$ a number of weight for height indices $\mathrm{Wt} / \mathrm{Ht}, \mathrm{Wt} / \mathrm{Ht}^{2}$ and $\mathrm{Wt} / \mathrm{Ht}^{3}$ were calculated, as described by Criqui et al (1982). The index $\mathrm{Wt} / \mathrm{Ht}^{2}$ is also known as the Body Mass Index (BMI) or Quetelet's Index. Multiple linear regression was used to analyse the results so that variables could be assessed jointly for their influence on running speed. For valid significance tests, multiple regression requires the residuals, that is the difference of the observed values from the predicted values, to be approximately Normally distributed. It was found that the variable finishing time resulted in slightly skewed residuals, and a more symmetrical distribution, and a better description of the data as measured by the multiple correlation coefficient was obtained from the variable running speed, defined as the inverse of finishing time. A step-up procedure (Armitage, 1971, p. 314) was used to obtain the best fitting model.

\section{RESULTS}

Of 221 finishers 98 (44\%) returned the questionnaire and of these 10 were women. A further 10 men completed the questionnaire but either did not start or failed to complete the race. The 10 women had an average finishing time of 100 minutes. Further analysis is restricted to the 88 men who completed both the questionnaire and the race. Table I compares the questionnaire results of the finishers and nonfinishers. Compared with the finishers the non-finishers were slightly more obese, and had trained slightly less, but none of the differences were significant.

One subject, had pulse rates on the first and second occasion of 94 and $98 \mathrm{bts} / \mathrm{min}$ respectively which are more than three standard deviations from the mean. These are unlikely to be true resting pulse rates, and so this subject was excluded from 
the modelling process. Only six competitors admitted to smoking, and their finishing times were not significantly different from the overall average.

TABLE I

A comparison of male finithers and non-finiahers.

\begin{tabular}{|c|c|c|c|c|}
\hline & \multicolumn{2}{|c|}{$\begin{array}{c}\text { Finishers } \\
n=88\end{array}$} & \multicolumn{2}{|c|}{$\begin{array}{c}\text { Non-finishers } \\
n=10\end{array}$} \\
\hline & Mean & Range & Mean & Range \\
\hline Age & 27.4 & $18-53$ & 23.1 & $18-40$ \\
\hline Ht (m) & 1.79 & $1.65-1.90$ & 1.76 & $1.65-1.85$ \\
\hline$W_{t}$ (kg) & 69.6 & $54.1-89.1$ & 69.5 & 57.3-98.6 \\
\hline BMI $\left(\mathrm{kg} / \mathrm{m}^{2}\right)$ & 21.6 & 18.1-25.9 & 22.2 & 19.8-28.7 \\
\hline $\begin{array}{l}\text { Kilometres per } \\
\text { woek }\end{array}$ & 39.7 & 0-104 & 34.2 & 13.64 \\
\hline Weeks training & 12.0 & $0-52$ & 13.4 & $4-30$ \\
\hline $\begin{array}{l}\text { Pulse rate } 1 \\
\text { (bts/min) }\end{array}$ & 59.0 & $40-94$ & 63.2 & $44-80$ \\
\hline $\begin{array}{l}\text { Pulse rate } 2 \\
\text { (bts/min) }\end{array}$ & 59.1 & $40-98$ & 65.4 & $55-78$ \\
\hline
\end{tabular}

The finishing time of those who returned the questionnaire (mean 92 minutes, range 64-120 minutes) was less than that of the non-responders (mean 97 minutes, range 91-127 minutes) and was close to being formally statistically significant $(z=1.8, p=0.07)$.

The correlations between running speed, resting pulse rate, the amount of training and anthropometric measures are shown in Table II. Values greater than $\mathbf{0 . 2 1}$ are formally significant at the $5 \%$ level and values over 0.27 significant at the $1 \%$ level. Running speed was negatively correlated with number of weeks training. Pulse rate was negatively correlated with number of weeks and also with height.

TABLE ॥

Corrolation of training mesecures, BaI and hoight with pulso rate and running speed.

\begin{tabular}{lccccc}
\hline & $\begin{array}{c}\text { Running } \\
\text { Speed }\end{array}$ & $\begin{array}{c}\mathrm{Km} / \\
\text { woek }\end{array}$ & $\begin{array}{c}\text { No. } \\
\text { Woeks }\end{array}$ & Height & $\begin{array}{c}\mathrm{BMI} \\
\left(\mathrm{Wt}_{\mathrm{t}} / \mathrm{Ht}^{2}\right)\end{array}$ \\
\hline Running Speed & 1.00 & $0.53^{* *}$ & $0.40^{* *}$ & 0.18 & $-0.41^{* *}$ \\
Pulse Rate 1 & $-0.53^{* *}$ & $-0.31 * *$ & -0.13 & $-0.33^{* *}$ & 0.16 \\
Pulse Rate 2 & $-0.35^{* *}$ & $-0.29 * *$ & -0.12 & $-0.30^{* *}$ & 0.16 \\
\hline
\end{tabular}

** $p<0.01$ on the null hypothesis of zero correlation

To examine how well running speed could be predicted a stepwise multiple regression was performed. The dependent variable was running speed (RS) in kilometres/hour, and the predictors were age, height $(\mathrm{Ht})$, weight $(\mathrm{Wt}), \mathrm{Wt} / \mathrm{Ht}, \mathrm{Wt} / \mathrm{Ht}^{2}$, $\mathrm{Wt} / \mathrm{Ht}^{3}$ pulse rate 1 (PR1), pulse rate 2 (PR2), kilometres per week (K), number of training weeks (NW) and "total distance" $(K \times N W)$. The most important predictor was kilometres per week $(K)$, followed by $B M I=W t / H^{2}, P R 2$ and $N W$. In terms of their relative contribution to the percentage variance explainable, $K$ explained $58 \%$ followed by BMI (30\%), PR2 $(6 \%)$ and NW $(6 \%)$.

The resulting equation is given by

$$
R S=21.3+0.028 K-0.31 B M I-0.037 \text { PR2 + 0.012 NW }
$$

Each coefficient is formally statistically significant at least at the $5 \%$ level. The percentage variance of running speed explained by the above equation is $47 \%$. This means that $53 \%$ of the variation in running speed has not been accounted for.

Table III gives some predicted running speeds for some typical runners, to show the association with different variables. Thus a person with a pulse rate of $50 \mathrm{bts} / \mathrm{min}$ training at $15 \mathrm{~km} / \mathrm{wk}$ can expect to run as fast as someone with a pulse rate of $70 \mathrm{bts} / \mathrm{min}$ training at $45 \mathrm{~km} / \mathrm{wk}$.

TABLE III

Predicted running epeeds and times to run a half marathon for typical velues of hoisht, wioht and pulse rate for two training regimes.

\begin{tabular}{|c|c|c|c|c|c|}
\hline \multirow[b]{2}{*}{$\begin{array}{c}W_{t} \\
(\mathrm{~kg})\end{array}$} & \multicolumn{4}{|c|}{ Training 15 km/wk for 12 weeks } & \multirow[b]{2}{*}{$\begin{array}{l}\text { Time for } 1 / 2 \\
\text { marathon } \\
\text { (mins) }\end{array}$} \\
\hline & $\underset{(m)}{H t}$ & $\begin{array}{c}\text { PR2 } \\
\text { (bts/min) }\end{array}$ & $\underset{\left(\mathrm{kg} / \mathrm{M}^{2}\right)}{\mathrm{BMI}}$ & $\begin{array}{l}\text { RS } \\
\mathrm{k} / \mathrm{hr}\end{array}$ & \\
\hline 60 & 1.70 & 50 & 20.8 & 13.6 & 93 \\
\hline 70 & 1.75 & 50 & 22.9 & 12.9 & 98 \\
\hline 80 & 1.75 & 50 & 26.1 & 11.9 & 106 \\
\hline 60 & 1.75 & 50 & 19.6 & 13.9 & 91 \\
\hline 70 & 1.80 & 50 & 21.6 & 13.3 & 95 \\
\hline 80 & 1.80 & 50 & 24.5 & 12.4 & 102 \\
\hline 60 & 1.70 & 70 & 20.8 & 12.8 & 99 \\
\hline 70 & 1.75 & 70 & 22.9 & 12.2 & 104 \\
\hline 80 & 1.75 & 70 & 26.1 & 11.2 & 113 \\
\hline 60 & 1.75 & 70 & 19.6 & 13.2 & 96 \\
\hline 70 & 1.80 & 70 & 21.6 & 12.6 & 100 \\
\hline 80 & 1.80 & 70 & 24.5 & 11.7 & 108 \\
\hline
\end{tabular}

Training 45 km/wk for 12 weeks

\begin{tabular}{lccccc}
$\begin{array}{c}W \mathrm{t} \\
(\mathrm{kg})\end{array}$ & $\begin{array}{c}\mathrm{Ht} \\
(\mathrm{m})\end{array}$ & $\begin{array}{c}\text { PR2 } \\
(\mathrm{bts} / \mathrm{min})\end{array}$ & $\begin{array}{c}\mathrm{BMI} \\
\left(\mathrm{kg} / \mathrm{m}^{2}\right)\end{array}$ & $\begin{array}{c}\mathrm{RS} \\
\mathrm{k} / \mathrm{hr}\end{array}$ & $\begin{array}{c}\text { Time for } / \mathrm{z} \\
\text { marathon } \\
(\mathrm{mins})\end{array}$ \\
\hline 60 & 1.70 & 50 & 20.8 & 14.4 & 88 \\
70 & 1.75 & 50 & 22.9 & 13.7 & 92 \\
80 & 1.75 & 50 & 26.1 & 12.7 & 100 \\
60 & 1.75 & 50 & 19.6 & 14.7 & 86 \\
70 & 1.80 & 50 & 21.6 & 14.1 & 90 \\
80 & 1.80 & 50 & 24.5 & 13.2 & 96 \\
60 & 1.70 & 70 & 20.8 & 13.6 & 93 \\
70 & 1.75 & 70 & 22.9 & 13.0 & 97 \\
80 & 1.75 & 70 & 26.1 & 12.0 & 106 \\
60 & 1.75 & 70 & 19.6 & 13.0 & 90 \\
70 & 1.80 & 70 & 21.6 & 13.4 & 94 \\
80 & 1.80 & 70 & 24.5 & 12.5 & 101 \\
\hline
\end{tabular}

PR2 = 2nd Pulse Rate

RS = Running Speed

\section{DISCUSSION}

The accuracy of the prediction equation, as judged by the percentage variance explained by the independent variates is comparable to the results of Tanaka and Matsuura (1982). They found that for distance running up to $40 \%$ of the variance could be explained by either anthropometric variables, or physiological variables. The results in this paper support their finding of a negative correlation between the Body Mass Index and running speed in distance runners. This is in contrast to Thomas et al (1983) who found a positive correlation between weight and running speed in distance runners. It would appear more reasonable to suppose that, allowing for height, the more obese subjects do not run as fast over long distances as their leaner colleagues. Compared with other simple obesity measures, $\mathrm{Wt}, \mathrm{Wt} / \mathrm{Ht}, \mathrm{Wt} / \mathrm{Ht}^{3}$, the fact that $\mathrm{Wt} / \mathrm{Ht}^{2}$ (the BMI) is the best predictor of running speed is interesting. If the speed at which one can run can be taken as a measure of cardiovascular fitness, then these results confirm Criqui et al (1982) that the BMI is the best simple index of obesity in cardiovascular studies.

Self-reported values for height tend to be overestimated, and those for weight underestimated. Stewart (1982) 
suggested that individual self-reported values for subjects with more than 12 years education be reduced by $2 \mathrm{cms}$ for height and increased $1.2 \mathrm{~kg}$ for weight. However, the regression equation was virtually unchanged with these adjusted values.

The response rate to the questionnaire was poor, but quite typical of sociological studies, and any study such as this is likely to find that fitter people are more willing to respond to a questionnaire. However, the range of abilities of the responders was wide, and representative of the whole group and so for estimating the regression equations the data should be adequate. As for any regression equation, the equation given here will not be such a good predictor if applied in a different race, but is given here so that the average runner can give himself a target to aim for. Extrapolation is unwise; according to the above equation, someone who did no training, i.e. $M=0, K=0$, with a BMI of $26 \mathrm{~kg} / \mathrm{m}^{2}$ and a resting pulse rate of $80 \mathrm{bts} / \mathrm{min}$ should still be able to complete the half marathon in just over two hours. Of course these results are conditional in him finishing at all!

Note from the relative contribution to the percentage variance explainable that the distance trained per week $(K)$ and the Body Mass Index account for the vast bulk of the regression, and that pulse rate and number of weeks trained, although statistically significant, are not such critical variables in the equation.

Most studies involve highly trained athletes and expensive laboratory facilities. This study has shown that useful results can be obtained from casual (i.e. not elite) runners and an inexpensive questionnaire. Subjects can reliably measure their own resting pulse rate. Having allowed for the amount of training and obesity, the resting pulse rate still remained a significant predictor of running speed, and thus could be useful for comparing runners who do similar amounts of training and are of similar build.

\section{ACKNOWLEDGEMENTS}

I would like to thank Mr. G. Barrell of the Department of Physical Education, University of Southampton, for his cooperation in this study, David Thomas for technical assistance and David Machin for many helpful comments on the manuscript.

\section{References}

Armitage, P. 1971 "Statistical methods in medical research". Oxford, Blackwell Scientific Publications.

Costill, D. L., Fink, W. J. and Pollock, M. L., 1976 'Muscle fibre com position and enzyme activities of elite distance runners". Med.Sci. Sports 8: 96-100.

Criqui, M. H., Klauber, M. R., Barrett-Connor, E., Holdbrook, M. J. Suarez, L. and Wingard, D., 1982 "Adjustment for obestiy in studies of cardiovascular disease". Am.J.Epidemiology 116: 685 91.

Hartung, G. H., 1982 "Physiological measures and marathon running performance in young and middle-aged males". J.Sports Med.Phys. Fitness 22: 366-70.

Khosla, T. and Campbell, H., 1982 "Resting pulse rate in marathon runners". Br.Med.J. 284: $1444-1445$.

Stewart, A. L. 1982 "The reliability of self-reported weight and height". J.Chron.Dis. 35: 295-309.

Tanaka, K. and Matsuura, Y., 1982 "A multivariate analysis of the role of certain anthropometric and physiological attributes of distance runners"'. Ann. Hum.Biol. 9: 473-82.

Thomas, T. R. Zebas, C. J., Bahrke, M. S., Aranjo, J. and Etheridge G. L., 1983 "Physiological and psychological correlates of success in track and field athletes". Brit.J.Sports Med. 17: 102-109.

\section{OBITUARY}

\section{Stephen Jackson Bell, MChS, SRCh}

It is a very sad task to record the untimely death of Stephen Bell after a short illness.

Stephen followed his father in the practice of Chiropody and although quiet and unassuming he was a diligent, enthusiastic practitioner popular with patients and colleagues alike. To me he was a good friend and steadfast colleague.

Stephen had been developing an interest in Podiatric Sports Medicines and was himself a keen shooter. He joined BASM in 1979, and had a special interest in the lower limb injuries, particularly in track and field athletes and joggers.

Stephen Jackson Bell is survived by his wife Carol and their two children. 